\title{
Short Stature in Isodicentric Y Chromosome and Three Copies of the SHOX Gene: Clinical Report and Review of Literature
}

\author{
Angelo Valetto $^{a}$ Veronica Bertini $^{\mathrm{a}}$ Angela Michelucci ${ }^{\mathrm{a}}$ Benedetta Toschi ${ }^{\mathrm{a}}$ \\ Eleonora Datic Giampietro I. Baroncelli ${ }^{b}$ Silvano Bertelloni ${ }^{b}$ \\ ${ }^{a}$ Division of Cytogenetic and Molecular Biology and ${ }^{b}$ Adolescent Medicine, Pediatric Division, Department of \\ Obstetrics, Gynecology and Pediatrics, Azienda Ospedaliero-Universitaria Pisana (AOUP), Pisa, and ' Division of \\ Pediatrics, San Giuseppe Hospital, ASL 11, Empoli, Italy
}

\section{Key Words}

GH-IGF1 axis · Short stature - SHOX · SHOX duplications ·

$\mathrm{Y}$ chromosome rearrangement

\begin{abstract}
Short stature homeobox gene (SHOX) mutations and pseudoautosomal region 1 (PAR1) deletions encompassing SHOX are known causes of Léri-Weill dyschondrosteosis and isolated short stature, while 3 copies of SHOX in cases with triple sex chromosome constitution are responsible for tall stature. Duplications involving SHOX have been rarely reported, and they were found in individuals with short, normal and tall stature. An adopted boy with short stature, isodicentric $Y$ chromosome and 3 copies of SHOX is described. Normal growth hormone $(\mathrm{GH})$ secretion and insulin-like growth factor 1 (IGF1) increase during an IGF1 generation test were found, ruling out impaired GH-IGF1 axis. No other organic or psychiatric causes of impaired growth were found. GH treatment improved linear growth, as reported in children with SHOX haploinsufficiency. This new report and the review of literature support that SHOX duplication may cause short stature, especially in those children with duplications of the $5^{\prime}$ SHOX regulatory elements. Chromosome analysis and detailed molecular characterization of the duplicated region
\end{abstract}

should be warranted in individuals with SHOX duplications in order to investigate the presence of occult chromosome imbalance. Additional reports and follow-up till adult height are needed to give conclusions on long-term efficacy and safety of GH treatment in short children with SHOX duplication.

ㄷ) 2016 S. Karger AG, Basel

The short stature homeobox gene (SHOX; NM_00451) encodes a homeodomain transcription factor involved in the regulation of chondrocyte differentiation and proliferation; it plays an important role in human skeletal growth, being specifically expressed in the growth plate [Marchini et al., 2007; Binder, 2011]. SHOX is located in the pseudoautosomal region 1 (PAR1) of the human sex chromosomes (Xp22.3 and Yp11.3). PAR1 genes do not undergo $\mathrm{X}$ inactivation and 2 copies of the SHOX gene are expressed, one from each of the sex chromosomes [Marchini et al., 2007; Iughetti et al., 2009; Binder, 2011].

Subjects with monoallelic mutations or deletions within the SHOX coding or enhancer regions have variable

A.V. and V.B. equally contributed to the genetic characterization of isodicentric $Y$ chromosome and the discussion on genetics.

\section{KARGER}

E-Mail karger@karger.com

www.karger.com/msy (c) 2016 S. Karger AG, Basel

1661-8769/16/0071-0019\$39.50/0
Silvano Bertelloni, MD

Dipartimento Materno Infantile Ospedale Santa Chiara-AOUP

Via Roma 67, IT-56125 Pisa (Italy)

E-Mail s.bertelloni@ao-pisa.toscana.it 
Table 1. Clinical data at adoption, at first clinical evaluation and during follow-up

\begin{tabular}{|c|c|c|c|c|c|}
\hline & \multirow[t]{2}{*}{ Adoption } & \multirow[t]{2}{*}{ First visit } & \multicolumn{3}{|l|}{$\mathrm{GH}$} \\
\hline & & & start & 6 months & 12 months \\
\hline Height, cm (SD) & $86.0(-3.1)$ & $118.8(-2.7)$ & $123.0(-2.8)$ & $128.3(-2.3)$ & $132.6(-2.1)$ \\
\hline Sitting/standing height ratio (percentile) & - & $0.532(97 \mathrm{th})$ & 0.535 (97th) & 0.527 (97th) & 0.525 (97th) \\
\hline Weight, kg & 9.9 & 26.0 & 30.6 & 31.7 & 32.5 \\
\hline
\end{tabular}

degrees of growth impairment, with or without the spectrum of skeletal anomalies consistent with the mesomelic skeletal dysplasia known as Léri-Weill dyschondrosteosis (LWD) [Iughetti et al., 2009; Binder, 2011]. SHOX haploinsufficiency has been found in $60-90 \%$ of patients with LWD and in $5-17 \%$ of children diagnosed as idiopathic short stature [Huber et al., 2006; Rappold et al., 2007; Rosilio et al., 2012; Wolters et al., 2013]. Patients with extra copies of SHOX due to sex chromosome trisomies are usually characterized by tall stature [Aksglaede et al., 2008], supporting the dosage-dependent action of SHOX on growth [Marchini et al., 2007; Iughetti et al., 2009; Binder, 2011].

Whereas patients with triple sex chromosome constitution are relatively common, complete or partial duplications limited to PAR1 including SHOX are extremely rare. Duplications of $S H O X$ have been described in individuals with short, normal or tall stature [Roos et al, 2009; Thomas et al, 2009; D’haene et al., 2010; Iughetti et al.; 2010; Benito-Sanz et al., 2011], leading to some uncertainty on the effect of SHOX duplication on growth.

Here, a boy with impaired growth and 3 copies of SHOX, due to a Y-chromosome rearrangement is described.

\section{Clinical Report}

The boy of Brazilian origin was born after an uncomplicated pregnancy and adopted by Italian parents when he was 3 years old. Normal birth weight was affirmed in his clinical record, but raw values and auxological data from his parents were not available.

Auxological data at adoption are summarized in table 1 showing impaired linear growth and body weight. The boy came to our attention on account of short stature at the age of 9.5 years. His weight and body mass index (BMI) were normal, but he did not reach adequate height for his age (table 1). He had mild cubitus valgus and a short neck, but Madelung deformity was not present. The sitting height/standing height ratio was at the 97 th percentile (table 1), suggesting body disproportion because of abnormal leg length. Bone age was 9.0 years $(-0.96 \mathrm{SD})$, carpal and epiphyseal angles were $135^{\circ}$ (n.v. $<120^{\circ}$ ) and $20^{\circ}$ (n.v. $<15^{\circ}$ ), respectively [Iughetti et al., 2010].

The occurrence of occult celiac disease or other chronic gastrointestinal disorder was ruled out by appropriate biochemical analysis; C-reactive protein, thyroid values, renal function, and albumin levels were normal (data not shown). Growth hormone (GH) deficiency was not found ( $\mathrm{GH}$ peaks $>10 \mathrm{ng} / \mathrm{ml}$ during 2 provocative GH tests). IGF1 values were in the normal range, but below the mean for age and sex $(114.0 \mathrm{ng} / \mathrm{ml} ;-0.62 \mathrm{SD})$. A normal increase was found after a IGF1 generation test (peak IGF1 value $331.2 \mathrm{ng} / \mathrm{ml}$; $\Delta$-increase $+190 \%$, n.v. $>15 \%$ ) [Pessoa de Queiroz et al., 2007]. No psychiatric causes of impaired growth were found.

\section{Methods}

\section{Clinical and Endocrine Evaluation}

Standing height was measured with a wall-mounted stadiometer. SD score of height and BMI [weight $(\mathrm{kg}) /$ height $\left(\mathrm{m}^{2}\right)$ ] was calculated according to WHO standards (www.who.int/ childgrowth/standards/en/). Sitting height/standing height ratio was evaluated according to Spanish normative values [de Arriba Muñoz et al., 2013]. Bone age was determined using X-ray of the nondominant hand and wrist and estimated according to Greulich and Pyle [1959]. Blood samples were drawn in the morning (between 8.00 and 9.00 a.m.), and serum was stored at $-20^{\circ} \mathrm{C}$ until analysis. Hormonal assays were performed by commercially available ELISA and chemiluminescence kits.

\section{Cytogenetic Analysis}

G- and Q-banded chromosomes of cultured peripheral blood lymphocytes and 100 metaphases were analyzed. Briefly, whole blood was cultivated in RPMI-1640 (Celbio, Milan, Italy), supplemented with $2 \%$ glutamine, $10 \%$ fetal calf serum, and $2 \% \mathrm{w} / \mathrm{v}$ PHA-M (Sigma, St. Louis, Mo., USA) for $72 \mathrm{~h}$ at $37^{\circ} \mathrm{C}$. Chromosome preparations were obtained according to standard techniques.

\section{FISH and Chromosome Painting}

FISH studies were performed at standard conditions using a whole Y chromosome-painting probe as well as probes specific for SRY and CEPX/CEPY centromere (Cytocell, Cambridge, 


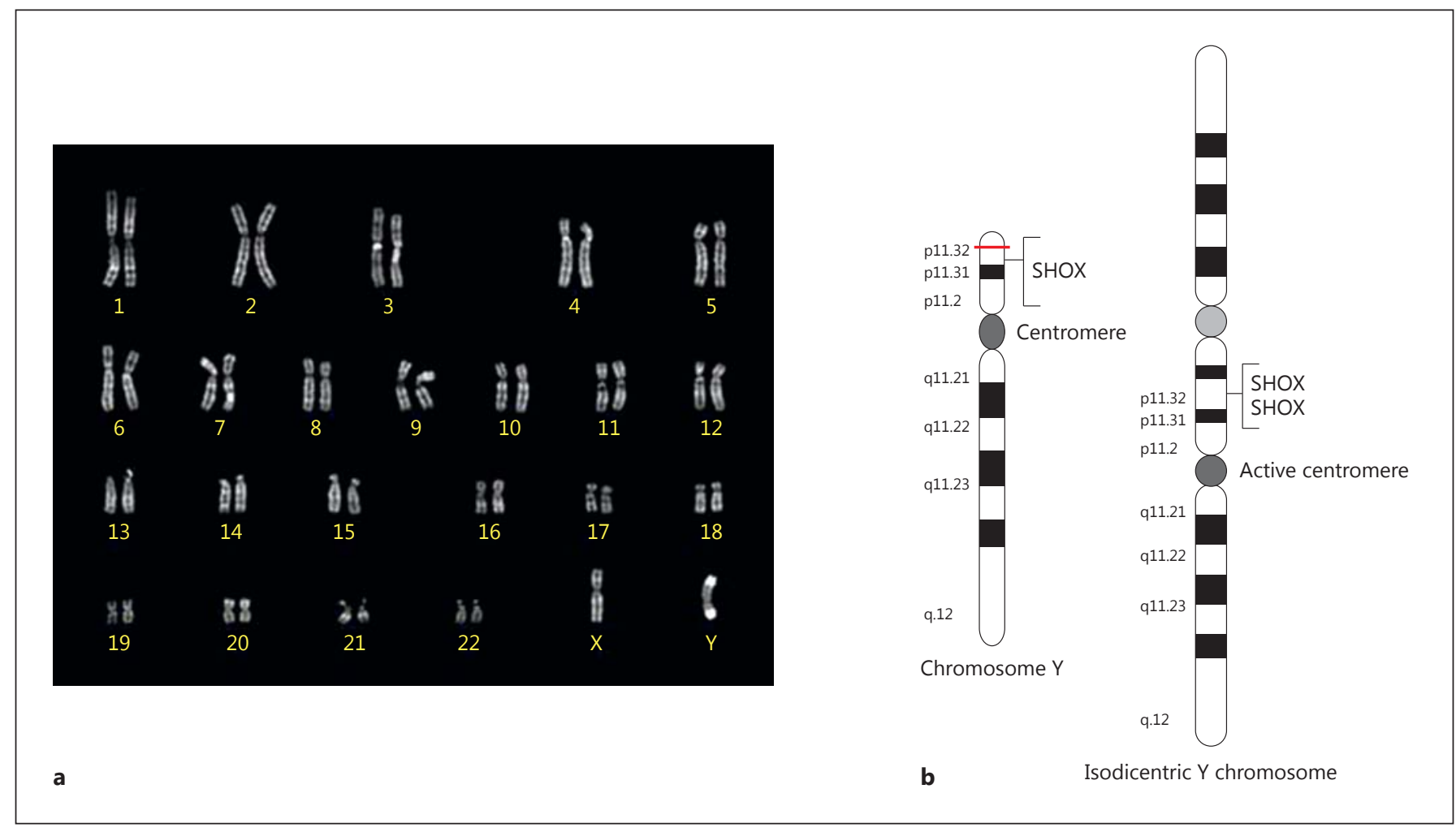

Fig. 1. Chromosome constitution of the boy with triple SHOX. a Q-banded karyotype showing the idic(Y). b Scheme of the structure of a normal Y chromosome and an idic(Y) chromosome.

UK). Each experiment was carried out according to the manufacturer's instructions. Signals were visualized by a Nikon microscope with an epifluorescent illuminator (Nikon, Tokyo, Japan) and were digitized for documentation with the CytoVision system (Nikon).

\section{Multiple Ligation Probe Assay}

MLPA reagents were obtained from MRC-Holland, Amsterdam, The Netherlands (SALSA MLPA kit P018-F1 SHOX). About $100 \mathrm{ng}$ of genomic DNA was used in the test, according to the manufacturer's protocol. Data normalization and data analysis were performed according to the manufacturer's recommendation.

\section{Array $\mathrm{CGH}$}

Array CGH was performed according to standard protocols. Briefly, genomic DNA was extracted from peripheral blood lymphocytes of the patient. This DNA and a male reference DNA were labeled differentially with cyanine 3 and 5, using standard procedures. Microarray experiments were performed on DNA microarrays $8 \times 60 \mathrm{~K}$ (Agilent Technologies, Santa Clara, Calif., USA) that have an $\sim 25-\mathrm{kb}$ average probe spatial resolution. Microarrays were scanned with an Agilent scanner G256BA. Hybridization data analysis was carried out with Agilent Technologies dedicated software. Search for copy number variation regions was performed using the Database of Genomic Variants (http://projects.tcag.ca/cariation/).

\section{Results}

A derivative $\mathrm{Y}$ chromosome was detected in all examined metaphases of the patient. FISH using a Y chromosome-painting probe confirmed the $\mathrm{Y}$ origin of this chromosome. SRY probe showed 2 hybridization signals, and 2 signals were apparent after hybridization with an alfacentromeric Y probe. PCR analysis showed that the azoospermia factor regions were present. The final karyotype was 46,X,idic $(Y, Y)($ qter $\rightarrow$ p11.32::p11.32 $\rightarrow$ qter $)$.ish $\operatorname{idic}(Y, Y)($ qter $\rightarrow$ p1 1.32::p11.32 $\rightarrow$ qter $)($ SRY++,DYZ3++). The structure of idic(Y) is shown in figure 1 .

MPLA showed an increase of about $50 \%$ of the peak areas corresponding to the probes in the PAR1. The probes from 01341-L20651 to 16858-L15742 were duplicated, including the SHOX gene (P018-F1 SALSA MLPA Kit). Sequencing of the coding region of SHOX did not detect any mutations.

Array CGH detected a 248-kb deletion starting from 11,091 to 248,336 (Yp11.32) and a 58-Mb duplication starting from position 248,336 (Yp11.32) to 59,335,913 (Yq12) (Hg19 reference map). 
After diagnosis of the SHOX duplication, treatment with recombinant GH was started at the dose of $0.33 \mathrm{mg} /$ $\mathrm{kg} /$ week and subdivided in 7 weekly doses. Growth velocity at 6 months $(10.6 \mathrm{~cm} /$ year $)$ and 12 months $(8.6 \mathrm{~cm} /$ year) of follow-up clearly increased in comparison with the value before the beginning of $\mathrm{GH}$ administration (4.2 $\mathrm{cm} /$ year). A reduction of the growth deficit and a decrease in the slight overweight were recorded during follow-up (table 1). No abnormal progression of bone age was observed (start of GH therapy: $-0.80 \mathrm{SD} ; 12$ months followup: $-0.62 \mathrm{SD})$.

\section{Discussion}

In this report, a child with short stature and 3 copies of $S H O X$ is described. He was adopted from a low-income social area, and malnutrition may be involved in both low weight and height at the age 3 years [Rogol and Hayden, 2014]. While BMI progressively normalized after adoption, height did not, suggesting the possibility of a specific cause for his short stature. Extensive investigations ruled out common organic or psychiatric causes of short stature [Rogol and Hayden, 2014; Ghione et al., 2015], not always explored in the previous short patients with SHOX duplications [D'haene et al., 2010; Iughetti et al., 2010; Benito-Sanz et al., 2011]. Normal GH secretion was found in the case reported by Iughetti et al. [2010]. In the patient of D'haene et al. [2010], data of clinical and endocrine investigations were not shown. In the series of BenitoSanz et al. [2011], the children were investigated according to criteria requiring the exclusion of $\mathrm{GH}$ deficiency [Cohen et al., 2008]. In the present case, normal GH secretion was also found. The normal increase in IGF1 during an IGF1 generation test, previously unreported in short patients with SHOX duplications, indicates normal GH sensitivity [Pessoa de Queiroz et al., 2007; Bertelloni et al, 2013].

So, the patient's karyotype constitution $[46, \mathrm{X}, \operatorname{idic}(\mathrm{Y})$ (p11.3)] may be involved in the origin of short stature. Different mechanisms can be proposed for the formation of this idic $(Y)$, both of them take place during the first meiotic division. The first mechanism involves a terminal deletion in Yp11.3, resulting in the loss of the telomeric $\mathrm{Yp}$ and in an unstable chromosome. End fusion of the 2 broken chromatids may occur to stabilize the deleted chromosome, followed by misdivision of the centromere (fig. 2). The second mechanism involves a misalignment between palindromic sequences in Y PAR1 along sister chromatids, that mediate a NAHR. The acentric fragment is likely lost during cell divisions (fig. 2a, b) [Lange et al., 2009].

The array CGH showed that the breakpoint of the $\operatorname{idic}(\mathrm{Y})$ is quite close to the Yp telomere, causing the deletion of $248 \mathrm{~kb}$ of the distal portion of PAR1 region. This region does not harbor known genes, whose deletion has been associated with pathological phenotypes. The rearranged $\operatorname{idic}(\mathrm{Y})$ chromosome (fig. 1) carries 2 copies of SHOX, leading to a trisomy of the gene. People with triple SHOX due to sex chromosome trisomy usually show tall stature [Aksglaede et al., 2008]. This finding is not always true in individuals with microduplications of PAR1 involving $S H O X$ or its regulatory sequences. In fact, cases with tall, normal and short stature have been reported [Roos et al., 2009; Thomas et al., 2009; D'haene et al., 2010; Iughetti et al., 2010; Benito-Sanz et al., 2011; Brosens et al., 2014].

The impaired growth pattern of some individuals with isolated SHOX microduplications suggests that expression of the allele harboring the duplication may be reduced or ablated, resulting in functional SHOX haploinsufficiency [Benito-Sanz et al., 2011]. The breakpoint of the microduplications can alter or disrupt its complex transcriptional regulation, in which either specific $5^{\prime}$ or $3^{\prime}$ regulatory sequences are involved for optimal gene expression [Ellison et al., 1997; Rao et al., 1997; Blaschke et al., 2003]. Regulatory sequences, such as enhancer elements, have been located in the proximity both of the $5^{\prime}$ and the $3^{\prime}$ gene regions, and they are necessary for temporal- and tissue-specific SHOX expression [Rosin et al., 2013]. The different phenotypes associated with SHOX duplications (table 2) may be related to their size, position and number of transcriptional enhancers within the duplicated interval [Benito-Sanz et al., 2011]. In the present case, the breakpoint is located $44 \mathrm{~kb}$ upstream of $S H O X$, where 5 highly conserved noncoding elements (CNEs) have been identified. All these CNEs are conserved in distantly related species and have enhancer activity in the developing chicken limb [Durand et al., 2010]. Even if all these CNEs are located in the duplicated region of idic(Y), the short stature of this boy may be related to a positional effect of the breakpoint on CNEs, or by disrupted activity of other regulatory sequences not yet characterized.

A literature review indicates that patients with short stature and different extents/positions of SHOX duplications are extremely rare. To our knowledge, only 17 cases including our patient have been described (female to male ratio 1.6:1.0; table 2). Multiple/complex Y rearrangements and mosaic cases were excluded. Few clinical data are reported in some studies and other phenotypic
Valetto/Bertini/Michelucci/Toschi/Dati/ Baroncelli/Bertelloni 
Fig. 2. Possible mechanisms of idic(Y) formation. A double-strand break occurs in the Y chromosome, and the broken ends are joined to stabilize the chromosome. This results in an $\operatorname{idic}(\mathrm{Y})$ and an acentric fragment (a). A misalignment, due to palindromic sequences in $\mathrm{Y}(\mathrm{p})$, occurs between sister chromatids followed by NAHR. Again this results in an idic(Yp) and an acentric fragment which has the length of Yp (b).

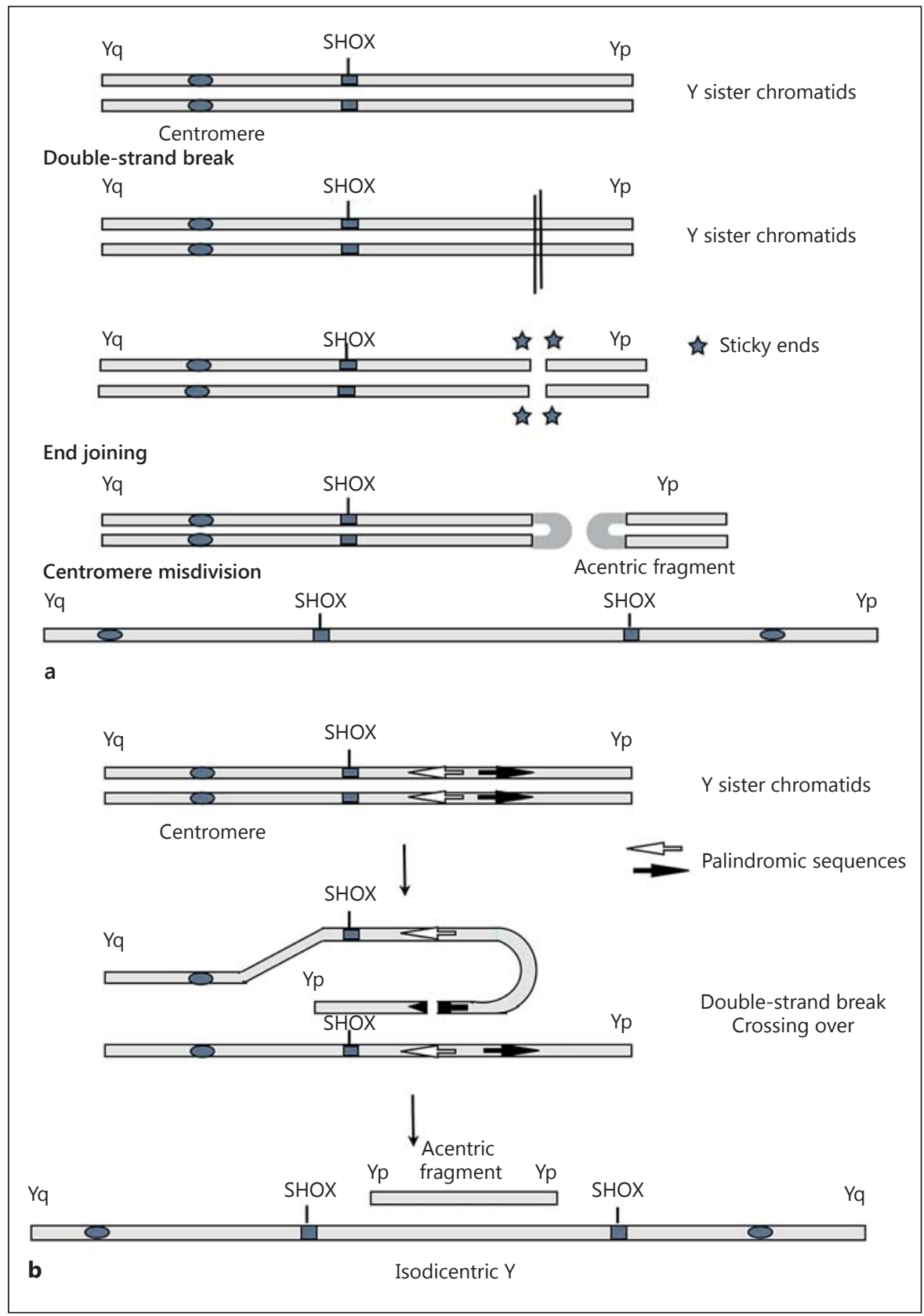

abnormalities were present in some patients (table 2). One girl with partial duplication of exons 2-6a was born small for gestational age [Benito-Sanz et al., 2011], which is a known cause of short stature [Rogol and Hayden, 2014]. Two additional small for gestational age babies with SHOX duplication and complex malformations resembling VACTERL association have been described, but their postnatal growth pattern was not shown [Brosens et al., 2014]. Phenotype may be LWD (47\%), mainly in par- tial duplications, or isolated short stature (53\%) in both complete and partial duplications, as in the present case (table 2). Madelung deformity was present in a minority of patients (44\%), all having partial SHOX duplications (table 2). Patients with LWD phenotype or Madelung deformity without short stature, who have a 5' SHOX duplication are also described [Thomas et al., 2009; BenitoSanz et al., 2011]. The causative role of SHOX duplication in other phenotypic or neurological abnormalities de- 
Table 2. Clinical and genetic features of children with partial or complete $S H O X$ duplication and short stature

\begin{tabular}{|c|c|c|c|c|c|c|c|}
\hline Authors & Sex & $\begin{array}{l}\text { Age, } \\
\text { years }\end{array}$ & Phenotype & $\begin{array}{l}\text { Height, } \\
\text { SD }\end{array}$ & $\begin{array}{l}\text { Madelung } \\
\text { deformity }\end{array}$ & Genotype & Notes \\
\hline Iughetti et al. [2010] & M & 13.9 & ISS & -3.25 & no & complete $S H O X-3^{\prime}$ region & $\begin{array}{l}\text { normal birth weight, parents with normal } \\
\text { height }\end{array}$ \\
\hline D'haene et al. [2010] & - & - & ISS & - & - & - & - \\
\hline \multirow{8}{*}{$\begin{array}{l}\text { Benito-Sanz et al. } \\
\text { [2011] }\end{array}$} & $\mathrm{F}$ & 13.0 & ISS & -2.57 & no & $5^{\prime}$ region-complete $S H O X-3^{\prime}$ region & slightly shortened neck \\
\hline & $\mathrm{F}$ & 6.7 & ISS & $-2,01$ & no & $5^{\prime}$ region-partial SHOX $\left(5^{\prime}-\mathrm{Ex} 3\right)$ & dermatitis atopica \\
\hline & M & 13.0 & LWD & -2.25 & yes & $5^{\prime}$ region-partial SHOX $\left(5^{\prime}-\mathrm{Ex} 3\right)$ & - \\
\hline & M & 10.7 & LWD & -1.80 & yes & partial SHOX (Ex2-6b) & - \\
\hline & M & 15.5 & LWD & -3.88 & yes & partial SHOX (Ex2-6a) & - \\
\hline & $\mathrm{F}$ & 5.0 & LWD & -4.13 & yes & partial SHOX (Ex2-6a) & - \\
\hline & $\mathrm{F}$ & 13.0 & LWD & -2.24 & yes & partial SHOX (Ex2-6a) & pyloric stenosis, urethral reflux \\
\hline & M & 10.0 & LWD & -2.06 & yes & partial SHOX (Ex2-6a) & - \\
\hline Present case & M & 9.5 & ISS & -2.70 & no & $5^{\prime}$ region-complete $S H O X$ & $\begin{array}{l}\text { referred normal birth weight, first case } \\
\text { treated with GH }\end{array}$ \\
\hline
\end{tabular}

ISS = Isolated short stature; SGA = small for gestational age.

scribed in some patients with SHOX duplication [Roos et al., 2009; D'haene et al., 2010; Iughetti et al., 2010; Brosens et al., 2014] requires further investigations, assessing the possible extraskeletal effect of this gene. Indeed, a definite genotype/phenotype correlation is currently not possible, due to the limited number of patients and the difficulties in comparing the extent of duplicated regions. In fact, the use of different in-house FISH clones, as well as different commercial kits for the MLPA analysis, determines some variability in probe specificity and localization. In addition, incomplete penetrance and variable expressivity of SHOX may play a role.

The effect of GH therapy in short patients with SHOX duplications was previously unreported. In our case, recombinant GH therapy induced a catch-up growth in the first year of treatment with an increase of growth velocity similar to that observed in SHOX haploinsufficiency [Binder, 2011; Iughetti et al., 2012; Massart et al., 2013], but efficacy in improving adult height and safety will require long-term follow-up.

In conclusion, $S H O X$ duplications may be a rare cause of short stature. Although expression studies of SHOX are not easy to be performed due to its tissue specificity and temporal regulation, a detailed molecular characterization of the PAR1 region is mandatory when SHOX dupli- cation is found, to better elucidate the correlations between different duplications and their phenotypic consequences. The beneficial effect of GH treatment in this child with SHOX duplication and short stature will be confirmed in other studies.

\section{Statement of Ethics}

The study was performed according to the Declaration of Helsinki II and standard protocol of short stature investigation in our Departments. Human recombinant GH treatment for SHOX gene deficiency was licensed by the Italian Regulatory Agency. Written informed consent was obtained from the parents before clinical, endocrine and genetic investigations.

\section{Disclosure Statement}

The authors have no conflicts of interest to declare.
Valetto/Bertini/Michelucci/Toschi/Dati/ Baroncelli/Bertelloni 


\section{References}

-Aksglaede L, Skakkebaek NE, Juul A: Abnormal sex chromosome constitution and longitudinal growth: serum levels of insulin-like growth factor (IGF)-I, IGF binding protein-3, luteinizing hormone, and testosterone in 109 males with $47, \mathrm{XXY}, 47, \mathrm{XYY}$, or sex-determining region of the $\mathrm{Y}$ chromosome (SRY)positive 46,XX karyotypes. J Clin Endocrinol Metab 93:169-176 (2008).

Benito-Sanz S, Barroso E, Heine-Suñer D, Hisado-Oliva A, Romanelli V, et al: Clinical and molecular evaluation of SHOX/PAR1 duplications in Léri-Weill dyschondrosteosis (LWD) and idiopathic short stature (ISS). J Clin Endocrinol Metab 96:E404-E412 (2011).

- Bertelloni S, Baroncelli GI, Dati E, Ghione S, Baldinotti $F$, et al: IGF-I generation test in prepubertal children with Noonan syndrome due to mutations in the PTPN11 gene. Hormones (Athens) 12:86-92 (2013).

-Binder G: Short stature due to SHOX deficiency: genotype, phenotype, and therapy. Horm Res Paediatr 75:81-89 (2011).

- Blaschke RJ, Töpfer C, Marchini A, Steinbeisser H, Janssen JW, Rappold GA: Transcriptional and translational regulation of the Léri-Weill and Turner syndrome homeobox gene SHOX. J Biol Chem 278:47820-47826 (2003).

-Brosens E, de Jong EM, Barakat TS, Eussen BH, D'haene B, et al: Structural and numerical changes of chromosome $\mathrm{X}$ in patients with esophageal atresia. Eur J Hum Genet 22: 1077-1084 (2014).

Cohen P, Rogol AD, Deal CL, Saenger P, Reiter $\mathrm{EO}$, et al: Consensus statement on the diagnosis and treatment of children with idiopathic short stature: a summary of the Growth Hormone Research Society, the Lawson Wilkins Pediatric Endocrine Society, and the European Society for Paediatric Endocrinology Workshop. J Clin Endocrinol Metab 93: 4210-4217 (2008).

-de Arriba Muñoz A, Domínguez Cajal M, Rueda Caballero C, Labarta Aizpún JI, Mayayo Dehesa E, Ferrández Longás Á: Sitting height/ standing height ratio in a Spanish population from birth to adulthood. Arch Argent Pediatr 111:309-314 (2013).
D'haene B, Hellemans J, Craen M, De Schepper J, Devriendt K, et al: Improved molecular diagnostics of idiopathic short stature and allied disorders: quantitative polymerase chain reaction-based copy number profiling of $S H O X$ and pseudoautosomal region 1. J Clin Endocrinol Metab 95:3010-3018 (2010).

Durand C, Bangs F, Signolet J, Decker E, Tickle C, Rappold G: Enhancer elements upstream of the SHOX gene are active in the developing limb. Eur J Hum Genet 18:527-532 (2010).

Ellison JW, Wardak Z, Young MF, Gehron Robey P, Laig-Webster M, Chiong W: PHOG, a candidate gene for involvement in the short stature of Turner syndrome. Hum Mol Genet 6: 1341-1347 (1997).

Ghione S, Maestro S, Dati E, Silvestri V, Baroncelli GI, Bertelloni S: Growth impairment and growth hormone-IGF-1 axis in infantile anorexia nervosa. J Pediatr Endocrinol Metab 28:999-1001 (2015).

Greulich WW, Pyle SI: Radiographic Atlas of Skeletal Development of the Hand and Wrist (Stanford University Press, Stanford 1959).

Huber C, Rosilio M, Munnich A, Cormier-Daire V; French SHOX GeNeSIS Module: High incidence of SHOX anomalies in individuals with short stature. J Med Genet 43:735-739 (2006).

Iughetti L, Appio P, Capone L, Madeo S, Predieri $\mathrm{B}$, et al: Short stature homeobox-containing gene and idiopathic short stature. Expert Rev Endocrinol Metab 4:241-250 (2009).

Iughetti L, Capone L, Elsedfy H, Bertorelli R, Predieri B, et al: Unexpected phenotype in a boy with trisomy of the SHOX gene. J Pediatr Endocrinol Metab 23:159-169 (2010).

Iughetti L, Vannelli S, Street ME, Pirazzoli P, Bertelloni S, et al: Impaired GH secretion in patients with SHOX deficiency and efficacy of recombinant human GH therapy. Horm Res Paediatr 78:279-287 (2012).

Lange J, Skeletsky H, van Daalen SKM, Embry SL, Korver CM, et al: Isodicentric Y chromosomes and sex disorders as byproducts of homologous recombination that maintains palindromes. Cell 138:855-869 (2009).

Marchini A, Rappold G, Schneider KU: SHOX at a glance: from gene to protein. Arch Physiol Biochem 113:116-123 (2007).
Massart F, Bizzi M, Baggiani A, Miccoli M: Height outcome of the recombinant human growth hormone treatment in patients with SHOX gene haploinsufficiency: a meta-analysis. Pharmacogenomics 14:607-612 (2013).

Pessoa de Queiroz AN, Collett-Solberg PF, Cardoso ME, Jusan RC, Vaisman M, Guimarães MM: IGF-I, IGFBP-3 and ALS generation test in Turner syndrome. Growth Hormon IGF Res 17:254-260 (2007).

Rao E, Weiss B, Fukami M, Rump A, Niesler B, et al: Pseudoautosomal deletions encompassing a novel homeobox gene cause growth failure in idiopathic short stature and Turner syndrome. Nat Genet 16:54-63 (1997).

-Rappold G, Blum WF, Shavrikova EP, Crowe BJ, Roeth $\mathrm{R}$, et al: Genotypes and phenotypes in children with short stature: clinical indicators of SHOX haploinsufficiency. J Med Genet 44: 306-313 (2007).

Rogol AD, Hayden GF: Etiologies and early diagnosis of short stature and growth failure in children and adolescents. J Pediatr 164 Suppl 5:S1-S14 (2014).

Roos L, Brøndum Nielsen K, Tümer Z: A duplication encompassing the SHOX gene and the downstream evolutionarily conserved sequences. Am J Med Genet A 149A:2900-2901 (2009).

Rosilio M, Huber-Lequesne C, Sapin H, Carel JC, Blum WF, Cormier-Daire V: Genotypes and phenotypes of children with SHOX deficiency in France. J Clin Endocrinol Metab 97:E1257E1265 (2012).

Rosin JM, Abassah-Oppong S, Cobb J: Comparative transgenic analysis of enhancers from the human SHOX and mouse Shox 2 genomic regions. Hum Mol Genet 22:3063-3076 (2013).

Thomas NS, Harvey JF, Bunyan DJ, Rankin J, Grigelioniene G, et al: Clinical and molecular characterization of duplications encompassing the human SHOX gene reveal a variable effect on stature. Am J Med Genet A 149A:1407-1414 (2009).

Wolters B, Lass N, Wunsch R, Böckmann B, Austrup F, Reinehr T: Short stature before puberty: which children should be screened for SHOX deficiency? Horm Res Paediatr 80: 273-280 (2013). 